\title{
Patient-level factors influencing hypertension control in adults in Accra, Ghana
}

\author{
Darlene Esinam Okai ${ }^{1}$, Adom Manu', Emefa Modey Amoah ${ }^{1}$, Amos Laar ${ }^{1}$, Joseph Akamah² and Kwasi Torpey ${ }^{1 *}$ (D)
}

\begin{abstract}
Background: Effective control of blood pressure is necessary to avert the risk of cardiovascular diseases from uncontrolled hypertension. Despite evidence on the benefits of hypertension control, rates of control in Ghana remain low. This study assessed the patient-level factors that influence hypertension control among adults in Accra, Ghana.

Methods: A total of 360 hypertensive patients from two hospitals in Accra, Ghana were enrolled in the study. Patient socio-demographic characteristics were tabulated and associations between patient characteristics and hypertension control were estimated using chi-square tests and logistic regression.

Results: Less than a quarter of the patients had a controlled blood pressure. The patient's sex [AOR $=3.53$ ( $95 \% \mathrm{Cl}$ : 1.73-7.25], educational at junior high school $[\mathrm{AOR}=3.52(95 \% \mathrm{Cl} 1.72-7.22)]$, senior and junior high school $[\mathrm{AOR}=2.64$ $(95 \% \mathrm{Cl} 1.40-6.66$ ] $]$ and $\mathrm{AOR}=3.06(95 \% \mathrm{Cl} 1.03-6.67)]$ and presence of a comorbidity [AOR $=2.41(95 \% \mathrm{Cl} 1.32 ; 4.42)]$ predicted BP control among patients. Dyslipidaemia $[A O R=0.31,[0.11-0.89)]$ an increased pill burden, and length of diagnosis of $2-5$ years $(A O R=0.27(0.1-0.73)]$ however, were associated with reduced $\mathrm{BP}$ control $[\mathrm{AOR}=0.32(95 \% \mathrm{Cl}$ : $0.18-0.57)]$. The majority of patients reported forgetfulness, side effects of medication and high pill burden as reasons for missing their medications.

Conclusion: Knowledge of hypertension among patients is low. Sex, formal education and the presence of comorbidity and more specifically dyslipidaemia influences blood pressure control. High pill burden and $2-5$ years since diagnosis negatively affects the attainment of blood pressure control.
\end{abstract}

Keywords: Hypertension, Blood pressure control, Pill burden, Ghana, Developing countries

\section{Background}

Hypertension is recognized as a public health issue worldwide. Despite the global policy agenda set to address this challenge, blood pressure control remains elusive and hypertension is the leading cause of cardiovascular disease (CVD) worldwide [1-4]. Although there is evidence to show that awareness, treatment, and adherence to antihypertensive medication are essential for hypertension control [5], all three factors remain low across different countries and various settings [6]. Africa, compared to the rest of the world, has the highest hypertension prevalence with $27 \%$ of adults being hypertensive [7].

\footnotetext{
* Correspondence: ktorpey@hotmail.com

${ }^{1}$ University of Ghana School of Public Health, Accra, Ghana

Full list of author information is available at the end of the article
}

Unlike more developed countries of the world, low and middle-income countries (LMICS) continue to experience significant mortalities from infectious diseases [8]. The epidemiologic transition in developing countries leaves in its wake a myriad of chronic diseases. The occurrence of CVDs in the presence of prevalent infectious diseases contributes to increased mortality and places many developing countries into a double burden of disease [9].

In Ghana, the Ghana Health Service (GHS) 2014 Annual Report attributed the highest outpatient cases between 2011 and 2014 to hypertension. Within that same period, the Greater Accra and Ashanti region recorded the highest number of diagnosed cases of hypertension totalling 152 , 545 and 140,947 respectively. In Ghana, 63\% of women and $86 \%$ of men that are hypertensive reported being unaware of their condition according to the Ghana 
Demographic Health Survey 2014 [10]. As a preventive measure, the number and proportion of facilities running NCD Clinics and providing screening services for hypertension and diabetes were increased.

Despite the existence of extensive evidence on the benefits of hypertension treatment, control has been unsatisfactory $[1,11,12]$. Worldwide, assessments show less than $50 \%$ of treated hypertensive patients reach their blood pressure goals; increasing their risk of hypertensioninduced complications [13]. Recent studies on hypertension control have shown that patient, clinician as well as the health environment/health system factors all influence the attainment of hypertension control [14-16].

Control rates of hypertension vary widely across and within populations. Various studies have reported rates of $32.9-49 \%$ among similar population groups [1, 16-18]. In Ghana, however, control rates reported are relatively lower and range from 24 to $42 \%$ [19-21]. The available studies that have established the high prevalence of uncontrolled hypertension in Ghana but found inconsistent associations between socio-demographic factors and blood pressure control [20,21]. Where patient level factors have been assessed, evidence shows poor control associated with the number of hypertensive medications, duration of diagnosis and access to medication [21].

The Seventh Report of the Joint National Committee (JNC 7) recommends that all patients be classified as normal $(120 /<80)$, pre-hypertensive $(120-80-139 / 89)$, or hypertensive based on the level of the systolic and/or diastolic Blood Pressure (BP). Hypertension control is therefore achieved when a hypertensive individual attains blood pressure targets of less than $140 / 90 \mathrm{mmHg}$. For patients with co-morbidities such as diabetes and/or CKD, targets are set even lower at $<130 / 80 \mathrm{mmHg}$ for beneficial treatment outcomes [22].

Target 6 of the nine endorsed global NCDS targets, call for member states to achieve a $25 \%$ reduction in elevated blood pressure within their specific settings [4]. Reducing hypertension-related mortality, therefore, requires that the proportion of patients with controlled hypertension increases. This study, therefore, focuses on patient-level factors influencing blood pressure control among hypertensive adults in the Greater Accra Region of Ghana. Data from this study will support calls to develop comprehensive policies that will inch the country closer to achieving the global targets of control of the condition and reducing the resulting mortalities.

\section{Methods}

\section{Study design}

This was a cross-sectional survey of adult hypertensive patients attending two hospitals in the Greater Accra Region of Ghana.

\section{Participants}

A total of 360 participants were interviewed in this study - 213 from the first and 147 from the second hospital respectively. Only adult subjects were included in the study (18 years and above).

Inclusion criteria: Hypertensive patients who have been on treatment for not less than a year.

Exclusion criteria: Pregnant women, patients who were taking drugs that could increase blood pressure and patients diagnosed with psychiatric conditions were excluded from the study.

\section{Sampling procedure}

A list of hypertensive patients given appointments for each day was obtained from the records department of both facilities. Numbers were assigned to the individuals on the list. The numbers were randomly selected using the Excel random number generation. An average of 50 to 60 patients was booked for each clinic day for both facilities with the facility with a higher caseload contributing 30-35 per day.

\section{Data collection method/ technique and tools}

A written informed consent (signed or thumb printed) was obtained from each participant Respondents who were unable to read, write or sign nominated an independent witness to attest to the consent process. Data was collected using a structured questionnaire composed of four different sections (Additional file 1). The first section of the questionnaire recorded a minimum of two and a maximum of five BP readings inclusive of previous visits to the hospital. This section was completed after accessing this information from the individual patient folders. The $\mathrm{BP}$ readings recorded were taken by the healthcare provider as part of the routine care provided at the clinic. Blood pressure readings were taken in the non-dominant arm using an automated sphygmomanometer with the patient in an upright sitting position after having rested for at least $10 \mathrm{~min}$. Blood pressure classification for patients with more than one visit was based on the averaging of 25 recorded readings $[22,23]$.

The second section consisted of questions on the sociodemographics of participants including age, sex, marital status, level of education and income level. Section three examined patients' knowledge about hypertension, its causes, and complications as well as comorbidities (dyslipidaemia, diabetes, stroke, and chronic kidney disease) and the associated medications. Information about the taking of non-prescribed drugs was also obtained. A final knowledge score was obtained for each respondent out of 13. The categorisation of knowledge was based on a tercile distribution. The respondents were scored on their knowledge of a normal adult blood pressure and the number of causes and complications of hypertension they knew of. 
Scores of 9-13 (representing the upper third) were considered as having "Good knowledge", scores of 5-8 (representing the middle third) were categorized as "Moderate knowledge" and scores of 1-4 (representing the lower third) were categorized as "Poor knowledge".

The next section assessed patients' perceptions about the control status of their hypertension as well as their perception of the efficacy of antihypertensive medications being taken. The final section sought to assess patient level factors such as adverse effects experienced from the use of antihypertensive medication, high pill burden /polypharmacy, cost of medications, forgetfulness, and belief in divine intervention or belief in being cured of hypertension.

The developed questionnaire was reviewed by subject matter experts for face and content validity for readability, clarity and comprehensiveness. Minor revisions were necessary. The tool was further revised, and pretested among hypertensive patients reporting for blood pressure management at a facility that served a similar population to the study areas. This was to determine performance in the field as planned [24].

\section{Data analysis}

Cross-tabulations of patient socio-demographic variables, factors influencing hypertension control were undertaken. A descriptive analysis was conducted using Pearson's $x^{2}$ and fishers exact where appropriate. The hypertension control status of each patient was determined by calculating the average of all SBP and DBP readings recorded. Binary logistic regression was conducted on sociodemographic and patient level factors to determine their influence on hypertension control. All predictor variables were entered in the regression model at once. Blood pressure control in logistic regression was coded as 0 for poor control and 1 for optimal control. All analyses were conducted in STATA and statistical significance was set at a 95\% confidence interval.

\section{Ethical considerations}

Ethical clearance was sought from the Ghana Health Service Ethical Review Committee with approval number (GHS-ERC: 037/12/17). Permission to conduct research at Ghana Health Service facilities was also sought from the Regional Directorate of Ghana Health Service, Greater Accra region and subsequently from the Municipal Directorates of both facilities.

\section{Results}

Socio-demographic characteristics of respondents

A total of 360 patients participated in the study. All participants resided in urban areas and were native Ghanaians. By sex, 105 males and 255 females were interviewed with the mean age of $61.9( \pm 10.7)$ with ages ranging from 27 to 94 years. More than half of the respondents were aged over 61 years. Respondents were mostly married, and few had attained tertiary education (4.7\%) (Table 1).

\section{Respondents' knowledge about hypertension}

Approximately $73.3 \%$ of respondents showed poor knowledge of hypertension, $25.6 \%$ showed moderate knowledge and only $1.1 \%$ showed good knowledge of hypertension (Table 1).

\section{Reasons for missing medication among respondents}

Table 2 presents the reported reasons for missed medication among the respondents. The majority (70.5\%) cited forgetfulness as the reason for missing their medication. Another reason that was prominently cited was the high pill burden.

Table 1 Socio-demographic characteristics of respondents

\begin{tabular}{|c|c|c|}
\hline Characteristic & Frequency $(n=360)$ & Percentage (\%) \\
\hline \multicolumn{3}{|l|}{ Age } \\
\hline Mean age $( \pm S D)$ & $61.9 \pm 0.56$ & \\
\hline $27-45$ & 19 & 5.28 \\
\hline $46-60$ & 142 & 39.44 \\
\hline $61-94$ & 199 & 55.28 \\
\hline \multicolumn{3}{|l|}{ Sex } \\
\hline Male & 105 & 29.17 \\
\hline Female & 255 & 70.83 \\
\hline \multicolumn{3}{|l|}{ Knowledge } \\
\hline Poor knowledge & 264 & 73.33 \\
\hline Moderate knowledge & 92 & 25.56 \\
\hline Good knowledge & 4 & 1.11 \\
\hline \multicolumn{3}{|l|}{ Marital Status } \\
\hline Single & 20 & 5.56 \\
\hline Married & 243 & 67.50 \\
\hline Divorced & 20 & 5.56 \\
\hline Widowed & 77 & 21.39 \\
\hline \multicolumn{3}{|l|}{ Educational Status $^{a}$} \\
\hline No formal education & 92 & 25.56 \\
\hline Primary & 109 & 30.28 \\
\hline Junior high & 85 & 23.61 \\
\hline Secondary & 57 & 15.83 \\
\hline Tertiary & 17 & 4.72 \\
\hline \multicolumn{3}{|l|}{ Income (US \$) } \\
\hline Less than $\$ 40$ & 209 & 58.06 \\
\hline$\$ 40-\$ 120$ & 112 & 31.11 \\
\hline$\$ 120-\$ 210$ & 30 & 8.33 \\
\hline$>\$ 210$ & 9 & 2.50 \\
\hline
\end{tabular}

aprimary: the first 6 years of formal education as primary. Junior high: year 7-9, Secondary: years 10-12. Tertiary: higher education 
Table 2 Reasons for missed medication among respondents $\left(n=291^{\mathrm{a}}\right)$

\begin{tabular}{lll}
\hline Reason & Frequency & Percentage \\
\hline Forgetfulness & 205 & 70.45 \\
High pill burden & 78 & 26.80 \\
Side effects of medication & 69 & 23.71 \\
Cost of medication & 12 & 4.12 \\
Does not believe in orthodox medicines & 16 & 5.50 \\
Believed was cured & 9 & 3.09 \\
Believe in divine intervention & 1 & 0.34
\end{tabular}

${ }^{a}$ Available for 291 participants who responded to reason for missing medication. Multiple response permitted

\section{Hypertension control among respondents}

Less than a quarter of patients achieved hypertension control (23.3\%). Various socio-demographic characteristics were assessed against hypertension control. By sex, among female respondents, 69 (27.1\%) had achieved hypertension control and 15 (14.3\%) of male respondents had achieved hypertension control. This association was found to be significant $(p<0.009)$. Table 3 contains further details on hypertension control across various socio-demographic factors.

\section{Associations between patient factors and hypertension control}

Assessing patients by comorbidity showed that $18 \%$ of patients who had no comorbidities had achieved hypertension control. However, more patients with some comorbidity had achieved hypertension control (23.3\%). Among patients with dyslipidaemia, 8.9\% had controlled hypertension $(p<0.006)$. Table 4 has further details of factors associated with hypertension control.

\section{Determinants of hypertension control}

Table 5 shows the determinants of hypertension control among patients with their crude and adjusted odds ratios (AOR). Females were 3.55 times more likely to have their BPs controlled compared to men $[$ AOR $=3.55(95 \%$ CI 1.72, 7.22)]. A $69 \%$ reduction in the odds of having controlled hypertension was identified among patients who suffered from dyslipidaemia as comorbidity, compared to those who did not suffer this comorbidity $[\mathrm{AOR}=0.31$ (95\% CI 0.11, 0.89)].

Taking a higher number of antihypertensive pills per day was also associated with a reduced likelihood of attaining hypertension control. Given that a respondent took 3-4 antihypertensive pills per day, the odds of having a controlled BP was reduced by $68 \%$ [AOR $=0.32$ (95\% CI 0.18, 0.57)] compared to those who took 1 to 2 pills. (Table 5).
Table 3 Socio-demographic factors and Hypertension control

\begin{tabular}{|c|c|c|c|c|}
\hline \multirow[t]{3}{*}{ Variable } & \multicolumn{2}{|c|}{ Controlled BP } & \multirow{3}{*}{$x^{2}$} & \multirow{3}{*}{$p$-value } \\
\hline & \multirow{2}{*}{$\begin{array}{l}\text { No } \\
\text { n (\%) }\end{array}$} & \multirow{2}{*}{$\begin{array}{l}\text { Yes } \\
\text { n (\%) }\end{array}$} & & \\
\hline & & & & \\
\hline \multicolumn{5}{|l|}{$\overline{\text { Age }}$} \\
\hline Mean age ( \pm SD) & $61.2 \pm 0.61$ & $64.1 \pm 1.31$ & & 0.012 \\
\hline \multicolumn{5}{|l|}{ Age categories } \\
\hline $27-45$ & 15(78.95) & $4(21.05)$ & 0.7991 & 0.671 \\
\hline $46-60$ & $112(78.87)$ & $30(21.13)$ & & \\
\hline $61-94$ & $149(74.87)$ & $50(25.13)$ & & \\
\hline \multicolumn{5}{|l|}{ Sex } \\
\hline Male & $90(85.71)$ & 15(14.29) & 6.7832 & 0.009 \\
\hline Female & $186(72.94)$ & $69(27.06)$ & & \\
\hline \multicolumn{5}{|l|}{ Marital Status } \\
\hline Single & 15(75.00) & $5(25.00)$ & 5.9367 & 0.115 \\
\hline Married & 195(80.25) & 48(19.75) & & \\
\hline Divorced & $13(65.00)$ & $7(35.00)$ & & \\
\hline Widowed & $53(68.83)$ & 24(31.17) & & \\
\hline \multicolumn{5}{|l|}{ Knowledge } \\
\hline Poor knowledge & $205(77.65)$ & $59(22.35)$ & & $0.701^{b}$ \\
\hline Moderate knowledge & $68(73.91)$ & $24(26.09)$ & & \\
\hline Good knowledge & $3(75.0)$ & $1(25.0)$ & & \\
\hline \multicolumn{5}{|l|}{ Educational Status $^{\mathrm{a}}$} \\
\hline No formal education & $74(80.43)$ & 18(19.57) & 8.4273 & 0.077 \\
\hline Primary & $90(82.57)$ & 19(17.43) & & \\
\hline Junior high & $56(65.88)$ & 29(34.12) & & \\
\hline Secondary & $43(75.44)$ & $14(24.56)$ & & \\
\hline Tertiary & 13(76.47) & $4(23.53)$ & & \\
\hline \multicolumn{5}{|l|}{ Income } \\
\hline Less than $\$ 40$ & 163(77.99) & $46(22.01)$ & 0.95 & 0.781 \\
\hline$\$ 40-\$ 120$ & $84(75.00)$ & $28(25.00)$ & & \\
\hline$>\$ 120$ & $29(74.36)$ & $10(25.64)$ & & \\
\hline Total & $276(76.67)$ & $84(23.33)$ & & \\
\hline
\end{tabular}

$\mathrm{n}$ : Frequencies, \%:row percentages

aprimary: the first 6 years of formal education as primary. Junior high: year 7-9, Secondary: years 10-12. Tertiary: higher education

${ }^{\mathrm{b}}$ Based on Fishers exact test

\section{Discussion}

The findings of this study are indicative both of low knowledge of hypertension and blood pressure control among patients. Factors that were significantly associated with BP control were sex, education and the presence of comorbidity. Females achieved BP control more than their male counterparts, a finding in congruence with recent evidence from the Ghanaian setting $[19,20]$. This improved control among females could be the result of higher levels of awareness and treatment of hypertension among females than males [19]. It is nonetheless a worrying observation 
Table 4 Associations between other patient factors and hypertension control

\begin{tabular}{|c|c|c|c|c|}
\hline \multirow[t]{3}{*}{ Variable } & \multicolumn{2}{|c|}{ Controlled BP } & \multirow{3}{*}{$x^{2}$} & \multirow{3}{*}{$p$-value } \\
\hline & \multirow{2}{*}{$\begin{array}{l}\text { No } \\
\text { n(\%) }\end{array}$} & \multirow{2}{*}{$\begin{array}{l}\text { Yes } \\
n(\%)\end{array}$} & & \\
\hline & & & & \\
\hline \multicolumn{5}{|c|}{ Comorbidity } \\
\hline No & $59(62.11)$ & $36(37.89)$ & \multirow[t]{2}{*}{15.2969} & \multirow[t]{2}{*}{$<0.001$} \\
\hline Yes & 217(81.89) & $48(18.11)$ & & \\
\hline \multicolumn{5}{|l|}{ Diabetes } \\
\hline No & $147(74.62)$ & $50(25.38)$ & \multirow[t]{2}{*}{1.0195} & \multirow[t]{2}{*}{0.313} \\
\hline Yes & 129(79.14) & $34(20.86)$ & & \\
\hline \multicolumn{5}{|l|}{ CKD } \\
\hline No & $262(75.72)$ & $84(24.28)$ & & \multirow[t]{2}{*}{$0.047^{c}$} \\
\hline Yes & $14(100.00)$ & $0(0.00)$ & & \\
\hline \multicolumn{5}{|c|}{ Dyslipidaemia } \\
\hline No & $225(74.01)$ & $79(25.99)$ & \multirow[t]{2}{*}{7.6921} & \multirow[t]{2}{*}{0.006} \\
\hline Yes & $51(91.07)$ & $5(8.93)$ & & \\
\hline \multicolumn{5}{|l|}{ Stroke } \\
\hline No & $262(76.83)$ & $79(23.17)$ & \multirow[t]{2}{*}{0.0997} & \multirow[t]{2}{*}{0.752} \\
\hline Yes & 14(73.68) & $5(26.32)$ & & \\
\hline \multicolumn{5}{|c|}{ Pills taken for comorbidity } \\
\hline $1-2$ & $84(80.77)$ & $20(19.23)$ & & \multirow[t]{3}{*}{$0.725^{c}$} \\
\hline $3-6$ & 130(83.87) & $25(16.13)$ & & \\
\hline $7-13$ & $3(75.00)$ & $1(25.00)$ & & \\
\hline \multicolumn{5}{|c|}{ Non-Prescribed Med ${ }^{\mathrm{b}}$. } \\
\hline No & $209(76.56)$ & $64(23.44)$ & \multirow[t]{2}{*}{0.0076} & \multirow[t]{2}{*}{0.930} \\
\hline Yes & $67(77.67)$ & $20(22.99)$ & & \\
\hline \multicolumn{5}{|c|}{ Length of diagnosis } \\
\hline 1 & $21(63.64)$ & 12(36.36) & \multirow[t]{4}{*}{11.9293} & \multirow[t]{4}{*}{0.008} \\
\hline $2-5$ & $112(84.21)$ & $21(15.36)$ & & \\
\hline $6-10$ & $91(78.45)$ & $25(21.55)$ & & \\
\hline $21-40$ & $52(66.67)$ & 26(33.33) & & \\
\hline \multicolumn{5}{|c|}{ No. BP pills taken per day } \\
\hline $1-2$ & $85(64.89)$ & $46(35.11)$ & \multirow[t]{3}{*}{15.978} & $<0.001$ \\
\hline $2-4$ & $191(83.41)$ & $38(16.59)$ & & \\
\hline Total & $276(76.67)$ & $84(23.33)$ & & \\
\hline
\end{tabular}

n: Frequencies,\%:row percentages

${ }^{a}$ Co-morbidity was defined as the presence of diabetes, chronic kidney disease or dyslipidaemia

${ }^{b}$ Non-prescribed medication refers to any drug the patient is currently taking that is not prescribed by the attending physician

'Fishers' exact value

considering the higher incidence of stroke among Ghanaian males than females [25].

Although knowledge of hypertension in this study was critically lower than available estimates, it is inconsistent with reports indicating poor knowledge of hypertension among Ghanaians $[20,21,26]$. These low levels of knowledge are nonetheless comparable to levels recorded in
Table 5 Socio-demographic determinants of hypertension control among respondents

\begin{tabular}{lll}
\hline Characteristic & UOR $[95 \% \mathrm{Cl}]$ & AOR $^{\text {a }}[95 \% \mathrm{Cl}]$ \\
\hline Age & Ref & Ref
\end{tabular}

$\begin{array}{lll}46-60 & 1.00[0.31-3.25] & 2.18[0.50-9.52] \\ 61-94 & 1.25[0.40-3.97] & 2.04[0.46-9.02]\end{array}$

Knowledge

Poor knowledge Ref Ref

Moderate knowledge $\quad 1.22[0.71-2.12] \quad 1.05[0.54-2.06]$

Good knowledge $\quad 1.56[0.12-11.34] \quad 1.22[0.08-19.54]$

Sex

Male Ref Ref

Female $\quad 2.23[1.21-4.11]^{*} \quad 3.33[1.65-6.71]^{* *}$

Education

No formal Education Ref Ref

$\begin{array}{lll}\text { Primary } & 0.88[0.42-1.77] & 1.24[0.55-2.78]\end{array}$

Junior High $\quad 2.13[1.08-4.21]^{*} \quad 3.06[1.4-6.66]^{*}$

Secondary $\quad 1.34[0.61-2.96] \quad 2.64[1.03-6.76]^{*}$

Tertiary 1.27[0.37-4.34] 1.51[0.32-7.09]

Length of diagnosis (years)

$1 \quad$ Ref Ref

$2-5$

6-10

$0.33[0.14-0.77]^{*} \quad 0.27[0.1-0.73]^{*}$

$0.48[0.21-1.11] \quad 0.52[0.19-1.4]$

$11-40 \quad 0.88[0.37-2.05] \quad 0.67[0.23-1.91]$

Comorbidity

Comorbidity present $\quad 2.76[1.64-4.64]^{*} \quad 0.41[0.22-0.75]^{* *}$

Dyslipidaemia

Dyslipidaemia Absent Ref Ref

Dyslipidaemia Present $\quad 0.28[0.11-0.72]^{* *} \quad 0.31[0.11-0.89]^{*}$

Stroke

Stroke absent Ref Ref

Stroke Present $\quad 1.18[0.41-3.34] \quad 1.9[0.57-6.38]$

No. BP pills taken per day

1-2 pills Ref Ref

3-4 pills $\quad 0.37[0.22-0.61]^{* * *} \quad 0.32[0.18-0.57]^{* *}$

UOR Unadjusted odds ratio a ${ }^{\text {a }}$ Ajusted for all items in the table AOR: Adjusted odds ratio* $p<0.05 ;{ }^{* *} p<0.01$; ${ }^{* * *} p<0.001$

*Primary: the first 6 years of formal education as primary. Junior high: year 7-9, Secondary: years $10-12$. Tertiary: higher education

South Africa where only $0.3 \%$ of respondents were found to have good knowledge [27]. Surprisingly whereas others have found significant associations between knowledge of hypertension and hypertension control [28, 29], no significant association between knowledge and hypertension control was observed in this study. These findings are similar to other studies conducted in Southern Africa [27, 30]. It is plausible that hypertension control levels among 
participants were low due to the poor knowledge of hypertension reported. This is particularly notable as good knowledge of hypertension has been reported to improve compliance to antihypertensive treatment and consequently the control of the disease [31].

In this study, blood pressure control was positively associated with junior high and secondary education compared to those with no formal education. A finding in contrast to recent district-level findings in Ghana but indicative of opportunities for health education among patients that have attained at least junior secondary education [21].

A larger proportion of patients in this study with comorbidities did not achieve BP control. It is plausible, that comorbid patients, may have encountered challenges in observing the treatment for blood pressure control. This finding is similar to reported studies that highlight reduced BP control among patients with dyslipidaemia [32, 33]. It is plausible that among such patients, treatment of the comorbidity may be suboptimal. This poses a challenge to the successful control of hypertension among such patients.

Among patients who report taking 3-4 blood pressure pills per day, the observed reduction in control may be a result of the challenges of high pill burden. Similar results from more developed settings showed that patients who were on three or more antihypertensive pills were likely to miss their medication or have a treatment gap compared to those who were being treated on two pills [34]. Although in some settings, patients are educated to appreciate the severity of their condition to mitigate these treatment gaps [35]. Furthermore evidence indicates reduced BP control with an increasing number of antihypertensive medications [21]. Blood pressure Control among patients with high pill burdens could be improved with the use of fixed-dose combination (FDC) poly-pills to simplify treatment [36-38].

The reported reasons for missed medications highlighted forgetfulness as the prime cause. For adult patients, it is plausible that forgetfulness is due to the competing psychosocial demands of daily life. Medication side effects, high pill burden, cost of medication, belief in divine intervention, belief that one is cured and distrust of orthodox medicine were reasons given by respondents for poor adherence. These reasons are nonetheless similar to those identified in a Nigerian study on hypertension medication adherence [18].

Our study is not without limitations. First, information concerning knowledge and management of hypertension was self-reported lending itself to recall and information bias. All other patient history and comorbidity was reviewed from records. This study also does not control for the different treatment types being used by participants on treatment. We recommend that physicianpatient communication on the importance of treatment for the control and improvement in the condition must be encouraged to foster awareness and adherence. There is also a need for treatment guidelines with an emphasis on the use of polypills to reduce pill burden and improve blood pressure control.

\section{Conclusion}

This study concludes that knowledge of hypertension among patients is low. Although sex, formal education and the presence of comorbidity and more specifically dyslipidaemia influences blood pressure control. High pill burden negatively affects the attainment of blood pressure control. The study also adds to the growing body of evidence highlighting the consistently low rates of hypertension control in Ghana over the last decade [39].

\section{Supplementary information}

Supplementary information accompanies this paper at https://doi.org/10. 1186/s12872-020-01370-y.

Additional file 1. English questionnaire developed for the study.

\section{Abbreviations}

AOR: Adjusted odds ratio; BP: Blood pressure; Cl: Confidence interval; CKD: Chronic kidney disease; CVD: Cardiovascular disease; DBP: Diastolic blood pressure; FDC: Fixed-dose combination; GHS: Ghana health services; LEKMA: Ledzokuku Krowor municipal assembly; LMICS: Low and middleincome countries; NCDs: Non-communicable diseases; SBP: Systolic blood pressure

\section{Acknowledgments}

We would like to the management and staff of the La Dadekotopon and Ledzokuku Krowor Municipal Assemblies, the La General and LEKMA hospitals, and the patients for their support during the study.

\section{Authors contributions}

$\mathrm{DEO}, \mathrm{KT}$, and $\mathrm{AM}$ conceptualized the research topic. DEO analyzed the data. $D E O, A M, E M A, A L, J A$, and $K T$ were major contributors in writing the manuscript. All authors read and approved the final manuscript.

\section{Funding}

No funding was obtained for this study.

\section{Availability of data and materials}

The datasets used and analysed during the current study are available from the corresponding author on reasonable request.

\section{Ethics approval and consent to participate}

Ethical clearance was sought from the Ghana Health Service Ethical Review Committee with approval number (GHS-ERC: 037/12/17). Permission to conduct research at Ghana Health Service facilities was also sought from the Regional Directorate of Ghana Health Service, Greater Accra region and the Municipal Directorates of both facilities. A written informed consent (signed or thumb printed) was obtained from each participant Respondents who were unable to read, write or sign nominated an independent witness to attest to the consent process. Informed consent was obtained from all participants after the objectives, procedures and potential risks and benefits of the study had been thoroughly explained to them. Approval for thumbprinted consent among participants who were unable to read, write or sign was granted during the protocol review.

\section{Consent for publication}

Not applicable.

\section{Competing interests}

The authors declare that they have no competing interests. 


\section{Author details}

${ }^{1}$ University of Ghana School of Public Health, Accra, Ghana. ${ }^{2}$ University of Ghana School of Medicine and Dentistry, Accra, Ghana.

Received: 18 October 2019 Accepted: 30 January 2020

Published online: 11 March 2020

\section{References}

1. Devkota S, Dhungana RR, Pandey AR, Bista B, Panthi S, Thakur KK, et al. Barriers to treatment and control of hypertension among hypertensive participants: a community-based cross-sectional mixed method study in municipalities of Kathmandu, Nepal. Front Cardiovasc Med. 2016;3:26.

2. Appel LJ. Lifestyle modification as a means to prevent and treat high blood pressure. J Am Soc Nephrol. 2003;14(suppl 2):S99-S102.

3. Ataklte F, Erqou S, Kaptoge S, Taye B, Echouffo-Tcheugui JB, Kengne AP. Burden of undiagnosed hypertension in sub-saharan Africa: a systematic review and meta-analysis. Hypertension. 2015;65(2):291-8.

4. Beaglehole R, Bonita R, Ezzati M, Alleyne G, Dain K, Kishore SP, et al. NCD Countdown 2025: accountability for the $25 \times 25$ NCD mortality reduction target. Lancet. 2014;384(9938):105-7.

5. Melgarejo JD, Maestre GE, Thijs L, Asayama K, Boggia J, Casiglia E, et al. Prevalence, Treatment, and Control Rates of Conventional and Ambulatory Hypertension Across 10 Populations in 3 Continents. Hypertension. 2017 70(1):50-8.

6. Khatib R, Schwalm JD, Yusuf S, Haynes RB, McKee M, Khan M, et al. Patient and healthcare provider barriers to hypertension awareness, treatment and follow up: a systematic review and meta-analysis of qualitative and quantitative studies. PLoS One. 2014;9(1):e84238.

7. World Health Organization. Factsheet on hypertension 2019 [updated 13 September 2019,. Available from: https://www.who.int/news-room/factsheets/detail/hypertension.

8. World Health Organization. Sustainable Development Goals Health and Health-Related Targets; 2016. p. 29-41.

9. Dennis T, Meera N, Binny K, Sekhar MS, Kishore G, Sasidharan S. Medication adherence and associated barriers in hypertension management in India. J Cardiovasc Dis Prev Control. 2011;6(1):9-13.

10. Ghana Statistical Service, Ghana Health Service, International. I. Ghana Demographic and Health Survey 2014. Rockville, Maryland, USA: GSS, GHS, and ICF International. 2015.

11. Agyemang C, Nyaaba G, Beune E, Meeks K, Owusu-Dabo E, Addo J, et al. Variations in hypertension awareness, treatment, and control among Ghanaian migrants living in Amsterdam, Berlin, London, and nonmigrant Ghanaians living in rural and urban Ghana-the RODAM study. J Hypertens. 2017:36(1):169-77.

12. Burnier M. Drug adherence in hypertension. Pathophysiol Pharmacother Cardiovasc Dis. 2015:919-33. https://doi.org/10.1007/978-3-319-15961-4 43.

13. Kearney PM, Whelton M, Reynolds K, Muntner P, Whelton PK, He J. Global burden of hypertension: analysis of worldwide data. Lancet. 2005;365(9455): 217-23.

14. Akintunde AA, Akintunde TS. Antihypertensive medications adherence among Nigerian hypertensive subjects in a specialist clinic compared to a general outpatient clinic. Ann Med Health Sci Res. 2015;5(3):173-8.

15. Ogedegbe G. Barriers to optimal hypertension control. J Clin Hypertens. 2008;10(8):644-6.

16. Oliveria SA, Lapuerta P, McCarthy BD, L'Italien GJ, Berlowitz DR, Asch SM Physician-related barriers to the effective management of uncontrolled hypertension. Arch Intern Med. 2002;162(4):413-20.

17. Bhandari S, Sarma PS, Thankappan KR. Adherence to antihypertensive treatment and its determinants among urban slum dwellers in Kolkata, India. Asia-Pac J Public Health. 2015;27(2):Np74-84.

18. Okwuonu CG, Ojimadu NE, Okaka El, Akemokwe FM. Patient-related barriers to hypertension control in a Nigerian population. Int J Gen Med. 2014;7: 345-53.

19. Awuah RB, Anarfi JK, Agyemang C, Ogedegbe G, Aikins ad-GJJoh. Prevalence, awareness, treatment and control of hypertension in urban poor communities in Accra, Ghana 2014;32(6):1203-10.

20. Sanuade OA, Boatemaa S, Kushitor MK. Hypertension prevalence, awareness, treatment and control in Ghanaian population: evidence from the Ghana demographic and health survey. PLoS One. 2018;13(11):e0205985.

21. Sarfo FS, Mobula LM, Burnham G, Ansong D, Plange-Rhule J, Sarfo-Kantanka $\mathrm{O}$, et al. Factors associated with uncontrolled blood pressure among
Ghanaians: evidence from a multicenter hospital-based study. PLoS One. 2018:13(3):e0193494

22. Chobanian AV, Bakris GL, Black HR, Cushman WC, Green LA, Izzo JL Jr, et al. Seventh report of the Joint National Committee on Prevention, Detection, Evaluation, and Treatment of High Blood Pressure. Hypertension. 2003;42(6): $1206-52$.

23. Mancia G, Fagard R, Narkiewicz K, Redon J, Zanchetti A, Bohm M, et al. 2013 $\mathrm{ESH} / \mathrm{ESC}$ guidelines for the management of arterial hypertension: the task force for the management of arterial hypertension of the European Society of Hypertension (ESH) and of the European Society of Cardiology (ESC). J Hypertens. 2013;31(7):1281-357.

24. Del Greco L, Walop W. Questionnaire development: 5. Pretest Can Med Assoc J. 1987;136(10):1025-6.

25. Sarfo FS, Acheampong JW, Appiah LT, Oparebea E, Akpalu A, Bedu-Addo G. The profile of risk factors and in-patient outcomes of stroke in Kumasi, Ghana. Ghana Med J. 2014;48(3):127-34.

26. Ghana Statistical Service (GSS), Ghana Health Service (GHS), ICFInternational. Demographic and Health Survey 2014. Rockville: GSS, GHS, and ICF International; 2015.

27. Olowe OA, Ross AJ. Knowledge, adherence and control among patients with hypertension attending a peri-urban primary health care clinic KwaZulu-Natal. Afr J Prim Health Care Fam Med. 2017:9(1):e1-7.

28. Abougalambou SS, Abougalambou AS, Sulaiman SA, Hassali MA. Prevalence of hypertension, control of blood pressure and treatment in hypertensive with type 2 diabetes in Hospital University Sains Malaysia. Diab Metab Syndr. 2011;5(3):115-9.

29. Morisky DE, Ang A, Krousel-Wood M, Ward HJ. Predictive validity of a medication adherence measure in an outpatient setting. J Clin Hypertens. 2008;10(5):348-54

30. Duncan P, Howe L, Manakusa Z, Purdy S. Determinants of blood pressure control in rural KwaZulu-Natal, South Africa. South Afr Fam Pract. 2014;56(6): 297-304.

31. Almas A, Godil SS, Lalani S, Samani ZA, Khan AH. Good knowledge about hypertension is linked to better control of hypertension; a multicentre cross sectional study in Karachi, Pakistan. BMC Res Notes. 2012;5(1):579.

32. Jani Y, Kamberi A, Ferati F, Rexhepi A, Pocesta B, Orovcanec N, et al. Influence of dyslipidemia in control of arterial hypertension among type-2 diabetics in the western region of the republic of Macedonia. Am J Cardiovasc Dis. 2014:4(2):58-69.

33. Raal FJ, Alsheikh-Ali AA, Omar MI, Rashed W, Hamoui O, Kane A, et al. Cardiovascular risk factor burden in Africa and the Middle East across country income categories: a post hoc analysis of the cross-sectional Africa Middle East cardiovascular epidemiological (ACE) study. Arch Public Health. 2018;76(1):15

34. Panjabi S, Lacey M, Bancroft T, Cao F. Treatment adherence, clinical outcomes, and economics of triple-drug therapy in hypertensive patients. J Am Soc Hypertens. 2013;7(1):46-60

35. Hashmi SK, Afridi MB, Abbas K, Sajwani RA, Saleheen D, Frossard PM, et al. Factors associated with adherence to anti-hypertensive treatment in Pakistan. PLoS One. 2007:2(3):e280.

36. Castellano JM, Sanz G, Penalvo JL, Bansilal S, Fernandez-Ortiz A, Alvarez L, et al. A polypill strategy to improve adherence: results from the FOCUS project. J Am Coll Cardiol. 2014;64(20):2071-82.

37. Cimmaruta D, Lombardi N, Borghi C, Rosano G, Rossi F, Mugelli A. Polypill, hypertension and medication adherence: the solution strategy? Int J Cardiol. 2018;252:181-6.

38. Huffman MD, Xavier D, Perel P. Uses of polypills for cardiovascular disease and evidence to date. Lancet. 2017;389(10073):1055-65.

39. Bosu WK, Aheto JMK, Zucchelli E, Reilly S. Prevalence, awareness, and associated risk factors of hypertension in older adults in Africa: a systematic review and meta-analysis protocol. Systematic Rev. 2017:6(1):192.

\section{Publisher's Note}

Springer Nature remains neutral with regard to jurisdictional claims in published maps and institutional affiliations. 